\title{
Ártemis y la ciudad en el Himno a Ártemis de Calímaco
}

\author{
María Alejandra RodonI \\ Universidad Nacional del Sur \\ alejandra.rodoni@uns.edu.ar
}

Recibido: 04-11-2014

Aceptado: 18-12-2014

\section{RESUMEN}

El presente trabajo tiene como objetivo el análisis de la faceta de Ártemis como diosa de ciudad, aspecto poco desarrollado en la literatura, pero que se despliega enfáticamente en un himno que presenta el crecimiento de la figura de Ártemis como diosa en sus atributos y funciones. En este himno Calímaco, a la vez que subsana la falta de un gran himno para la diosa al estilo de los Himnos Homéricos más extensos, incorpora a la tradición literaria la dimensión cultual y ciudadana de Ártemis, de enorme importancia en la época helenística, y, al intentar trazar un cuadro abarcador de los cultos y templos que le están dedicados, adopta una perspectiva marcadamente panhelénica, que armoniza con los propósitos de la política cultural y religiosa de los Ptolomeos.

Palabras clave: Ártemis, himno, ciudad.

\begin{abstract}
This work is intended to analyze Artemis' facet as city goddess, an aspect not much developed in literature, but emphatically displayed in a hymn that presents the growth of Artemis' figure as goddess in her attributes and functions. In this hymn, Callimachus repairs the lack of a great hymn for the goddess in the style of the more extensive Homeric Hymns, and, at the same time, incorporates to the literary tradition the cult and city dimension of Artemis, which was of great importance in Hellenistic times. Furthermore, by trying to draw an encompassing picture of the cults and temples dedicated to her, Callimachus adopts a strong Panhellenic perspective, which harmonizes with the intention of cultural and religious policies of the Ptolomies.
\end{abstract}

Keywords: Artemis, hymn, city.

El Himno a Ártemis de Calímaco ha llamado la atención de los críticos por incorporar la dimensión ciudadana de la diosa en una forma nunca antes desarrollada en literatura. Si bien existen antecedentes literarios en la Oda 11 de Baquílides y el fragmento 348 de Anacreonte, la mayor parte de la literatura, ya desde la Ilíada, presenta a la diosa como «Señora de las Fieras» ( $\pi$ ćtvı $\theta \eta \rho \tilde{\omega} v$ ), joven cazadora indómita que vaga por las montañas y se muestra feroz con quienes subestiman u ofenden su poder.

Es conocido el artículo de Peter Bing y Volker Uhrmeister (1994), en el que con gran lucidez demuestran la unidad del Himno 3. En efecto, los autores postulan como 
tema del mismo el crecimiento de Ártemis, desde niña pequeña hasta su plenitud como diosa Olímpica, y la realización de su poder en su ambiente mítico y cultual. ${ }^{1}$ El $\mathrm{Him}$ $n o$ abre con una escena de la diosa niña sentada en las rodillas de su padre ${ }^{2}$, en la que pide a Zeus todas aquellas cosas que la caracterizarán como diosa en la literatura: virginidad, flechas, un arco, antorchas, una túnica corta, un coro, todos los montes y una sola

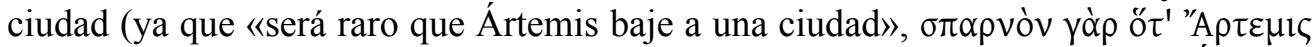

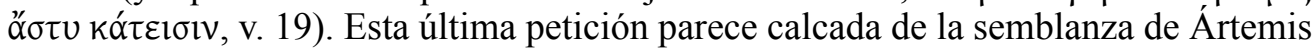
que figura en el Himno Homérico a Afrodita:

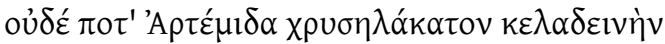

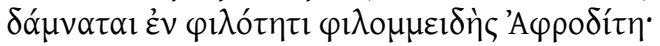

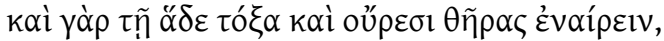

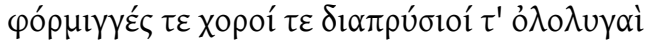

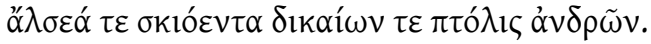

Tampoco a Ártemis de áureas flechas, resonante, subyuga en amor Afrodita, amante de la risa. Pues a ella le agradan los arcos, y matar fieras en los montes, las liras, los coros y los penetrantes gritos, los bosques sombríos y una ciudad de hombres justos. (HH 5, vs. 16-20).

Sin embargo, pese la petición de la diosa niña, su padre le concede no una, sino treinta ciudades que sólo serán de ella, además de las que compartirá con otros dioses, y le asigna también la protección de los caminos y de los puertos (vs. 31-39), confirmando sus palabras con un gesto de su cabeza. ${ }^{3}$ Este constituye el primer paso en el Himno en la representación de Ártemis como diosa de ciudad.

En los versos que siguen Ártemis se dedica a reunir sus atributos: las ninfas, sus armas (el arco y las flechas que encarga a los Cíclopes), los perros que le da el dios Pan en Arcadia (vinculación con el mundo de la caza), las ciervas que tirarán de su carro de oro. ${ }^{4} \mathrm{Al}$ apuntar su arco de plata, lo dispara primero a los árboles, y a un animal salvaje; al hacerlo por cuarta vez, lo hace contra una ciudad de malvados (vs. 121-123). El arco se convierte entonces en el símbolo del lazo entre la diosa y el reino que Zeus le ha impuesto: el de la ciudad. ${ }^{5} \mathrm{El}$ arma de la cazadora, con la que se mueve en el mundo de las fieras, el arco, es lo que la vincula también con la ciudad, ya sea para castigarla o para protegerla ${ }^{6}$ (como se dirá más tarde que hace con Éfeso, v. 258). En el castigo de la ciudad de hombres injustos, así como en las bendiciones que otorga a quienes mira

${ }^{1}$ Bing-Uhrmeister (1994: pág. 20).

2 Esa escena es reelaboración de la de Ilíada 21.481-8. Cf. Petrovic (2010: pág. 223).

${ }^{3}$ Escena relacionada con Iliada 1.524-530.

${ }^{4}$ De oro son también sus armas y su cinturón (vv. 110-112), lo que constituye «un signo tradicional de epifanía del poder ilimitado de un dios». Cf. Bing-Uhrmeister (1994: pág. 23).

${ }^{5}$ Bing - Uhrmeister (1994: pág. 24).

${ }^{6}$ No deja de resultar llamativo que el arco sea fabricado por los Cíclopes, quienes en la Oda 11 de Baquílides — donde Ártemis desempeña un rol importante como diosa de ciudad — son artífices de la

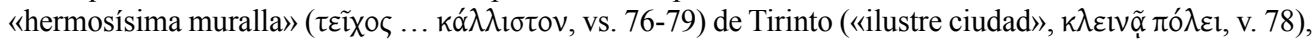
encomendada por orden de Zeus para poner fin a las disensiones de los Abántidas (vs. 69-81). 
propicia, asume el papel tradicional atribuido a su padre (Ilíada, 16.384-392; Hesíodo, Trabajos y días, vs. 225ss.; Calímaco, Himno a Zeus, vs. 79-85). Esta relación especial con él se ve reforzada por el hecho de que su antorcha ${ }^{7}$ sea encendida con los rayos de Zeus, con los que el dios castiga la injusticia: ${ }^{8}$

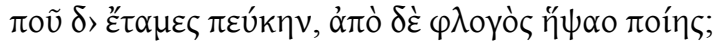

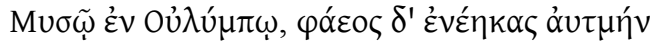

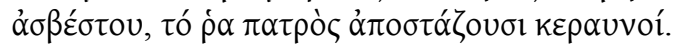

¿Dónde cortaste el pino de tu antorcha y en qué llama la encendiste? En el (monte) Olimpo de Misia, y le infundiste el soplo de luz inextinguible, que destilan los rayos de tu padre. (vs. 116-118)

De esta forma, y por medio de su intervención en el dominio de la ciudad, se revela en su totalidad como hija de su padre, al impartir justicia a través de su arco de plata, y como hermana de Apolo, quien también usa su arco en forma retributiva, función recordada por su epíteto homérico ápyvpótołoc. El aspecto vengativo de Ártemis y

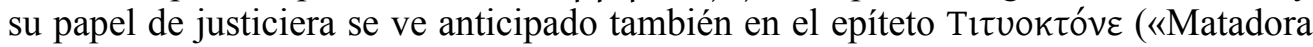
de Ticio», v. 110), revelador de un sentido personal de justicia que permite augurar su reacción ante la ciudad de los injustos. ${ }^{9}$

El desarrollo de la diosa hacia la edad adulta es, entonces, un desarrollo hacia la civilización, que culmina con la plegaria del poeta para formar parte, él y sus amigos, de quienes disfrutan las bendiciones de la diosa (es decir, de la ciudad de los Justos): ${ }^{10}$

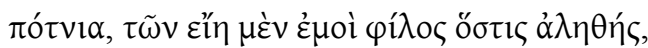

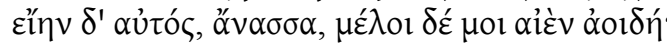

Señora, que forme parte de ellos quien es mi amigo verdadero; que forme parte de ellos yo mismo, soberana, y que la poesía siempre sea mi ocupación. (vs. 136-137)

A continuación el poeta describe el tema de su futuro canto:

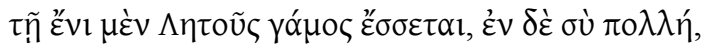

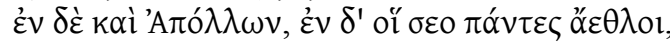

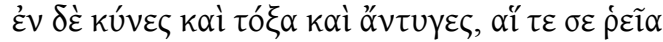

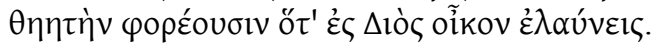

${ }^{7}$ El epíteto $\varphi \propto \varepsilon \sigma \varphi o ́ p \varepsilon$ (v. 204) «portadora de luz» también estaría relacionado con su rol en la vida de la ciudad, ya que «luz» frecuentemente significaba «vida» o «salvación» en griego, y más de una leyenda relataba la intervención de Ártemis en una situación difícil para la comunidad. Cf. BREMER (1994: pág. 17).

${ }^{8}$ BiNG - Uhrmeister (1994: pág. 25).

${ }^{9}$ Bing-Uhrmeister (1994: págs. 24-25).

${ }^{10}$ Sobre la inversión que hace Calímaco del modelo hesiódico, ver BING - UhrmeISTER (1994: págs. 25-26). 
En él estarán las bodas de Leto, en él estarás tú muchas veces, y Apolo, y todas tus hazañas, y tu jauría y tu arco, y el carro que fácilmente te conduce esplendorosa cuando lo guías a la morada de Zeus. (vs. 138-141)

El futuro canto del poeta se funde con el canto presente; es efectivamente el Himno a Ártemis que está ante nosotros. ${ }^{11}$ Por lo tanto él ya disfruta del favor de la diosa, que es la que habilita al poeta a cantar. Y eso es posible porque ella ha otorgado sus bendiciones a la ciudad que él habita. ${ }^{12}$

Luego de describir su llegada al Olimpo, ya adquirido su estatus de diosa, y de cantar a las Ninfas que la rodean en un coro tan bello que hace detener a Helios prolongando el día (vs. 180-182), sigue la enumeración de los lugares y compañeras favoritos de Ártemis, introducidos por una serie de preguntas en la que el poeta pide respuesta a la deidad, para contarlo él mismo a los demás:

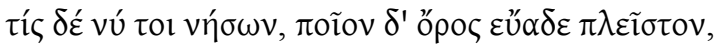

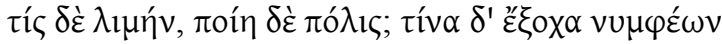

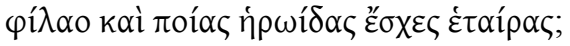

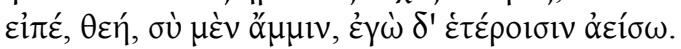

¿Cuál de las islas, qué montaña te agrada más? ¿Qué puerto, qué ciudad? ¿A cuál de las ninfas has amado sobre todas, y qué heroínas tuviste como compañeras? Dímelo a mí, diosa, y yo lo cantaré a los demás. (vs. 183-186)

Comenzando por Britomartis, cuya historia suministra el aition para el epíteto «Dictina» con que la invocan los cretenses, continúa la mención de otras favoritas (Cirene, Procris, Anticlea, Atalanta). La descripción de la afinidad de Ártemis con las ninfas sirve indirectamente a la caracterización de la diosa: se enfoca sobre su entorno más que sobre ella misma, y nos transporta, por medio del mito, a distintos lugares del mundo griego (Creta, Tesalia, Arcadia).

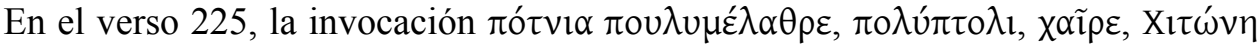
(«Señora de las muchas moradas, de muchas ciudades, salud, Quitona») anticipa el tema de la sección del Himno que sigue: el ámbito cultual, sección en que Ártemis deja de ser el tema mítico del mismo y se convierte en el objeto de culto. Estos epítetos, además, la confirman en su carácter de diosa ciudadana, otorgado por Zeus.

La sección comienza con una enumeración de lugares en los que la diosa recibe culto, que da cuenta de su amplia difusión: en los versos 225-250, el hablante relata, en efecto, diversos actos fundadores llevados a cabo en lugares tan diseminados como Mileto, Samos, Arcadia y Éfeso, vinculados a ella a través del mito. La primera fundación que se nombra es la de Mileto por Neleo, en la que la diosa actúa como guía

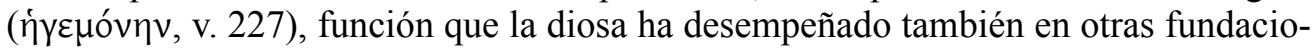

${ }^{11}$ Bing - Uhrmeister (1994: pág. 27).

${ }^{12}$ Según Bing - Uhrmeister (1994: págs. 27-28), hay aquí un elogio velado a la Alejandría ptolemaica, ya que en ella se da el ideal cívico de ciudad en que la armonía, tanto política como musical, existe realmente. 
nes, como la de Marsella. ${ }^{13}$ Además de guía, y por lo tanto beneficiaria de la expedición, porque de esa forma ella difunde su propio culto, ejerce también el papel de civilizadora, al llevar el modelo de la ciudad griega a lugares distantes. La confirmación de la implantación del culto en la colonia está en el verso 226, que vincula pasado y

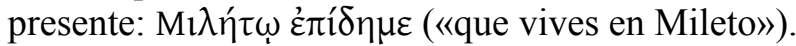

La expedición que se menciona a continuación es ahora militar: la de Agamenón a Troya, en la que Calímaco otorga a Ártemis un papel central. El poeta se aparta del relato tradicional ubicando el episodio de Áulide en $\operatorname{Samos}^{14} \mathrm{y}$ cambiando la ofrenda a la diosa: en lugar de su hija es el timón de su nave, que deposita en el templo de la deidad. De esta forma, Ártemis es la que encamina, la que orienta la expedición en lugar del timón que se le ofrece. Al ser el timón depositado en el templo (v. 229), corresponde a la diosa asegurar la dirección. El Himno acuerda entonces a Ártemis un papel muy importante en la campaña panhelénica: ella es el agente motor de una expedición destinada a restañar el honor ofendido de los griegos, lo que expresa la amplitud de su poder. Por la evocación de este episodio legendario, se ofrece un ejemplo tangible del aura de la diosa en un nivel panhelénico, en la medida en que la guerra de Troya fue una expedición llevada conjuntamente por todos los griegos. La mención del don de Agamenón, además, evoca la expansión del culto de Ártemis en esta isla del mar Egeo. ${ }^{15}$

La mención de otros dos actos de devoción cumplidos en regiones distintas subraya el radio extendido del culto de la diosa. El primero es el de Preto, rey de Tirinto, uno de los protagonistas de la Oda 11 de Baquílides. Las hijas de Preto, nos dice la Oda, se atrajeron la cólera de Hera: penetraron, siendo aún vírgenes, en un santuario de la esposa de Zeus y proclamaron la superioridad de su padre Preto en riquezas. Irritada, la diosa las hundió en una locura que las hizo errar en las montañas de Azinis. Sólo la intervención de Ártemis, a ruegos de Preto, permitió la curación de las muchachas, quienes le testimoniaron su reconocimiento construyendo un templo, instituyendo un sacrificio y creando un coro femenino en su honor. En Calímaco es el padre, no las hijas, quien erige dos templos (no uno) en su honor: uno de Ártemis Coria (Kopín, v. 234, de koṽpac, «doncellas», refiriéndose a las jóvenes Prétides), y otro en Lusos, de Ártemis Hemera («Aplacadora», que remite a la locura de las doncellas, calmada por la diosa). Preto encarna entonces la figura emblemática en la implantación del culto de la diosa en la región de Arcadia, ${ }^{16}$ y sus gestos constituyen actos fundadores de una nueva era cultual de Ártemis. Su agradecimiento sobrepasa largamente el gesto individual, en la medida en que concierne en adelante a una comunidad entera, consagrada a la celebración de la diosa en sus nuevos templos.

${ }^{13}$ VAmvoury RuFfy (2004: págs. 261-262).

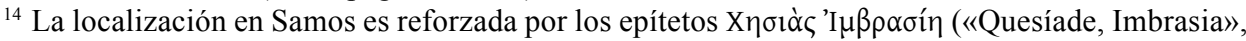
v. 228), ubicados inmediatamente al relato del don de Agamenón y que aluden a un cabo y un río de la isla, respectivamente.

${ }^{15}$ Donde, según Heródoto 3.48, existía un templo en su honor. Cf. VAmvoury RufFy (2004: pág. 263 y n. 168).

${ }^{16}$ Según Vamvoury Ruffy (2004: pág. 264, n. 172), Calímaco se inscribía en una tradición que tiene a este rey por fundador de muchos templos de la diosa, en Sición, Argos, etc. 
Finalmente, el Himno se desplaza a Éfeso para asistir a otro acto fundador, el del Artemision de Éfeso, llevado a cabo por las Amazonas (vv. 237-250), mujeres belicosas que veneraban particularmente a Ártemis y cuyo modo de vida se asemejaba fuertemente al modo de acción de esta: se dedicaban regularmente a la caza y mantenían una existencia libre del yugo del hombre. Ellas erigieron una imagen de la diosa ( $\beta p \varepsilon ́ \tau \alpha \varsigma$, v. 238) en las inmediaciones de Éfeso. Hippo, su reina, llevó a cabo luego un rito y sus compañeras ejecutaron una danza armada en torno de la estatua ( $\pi \rho u ́ \lambda_{\imath} v$, v. 240), seguida de una danza coral. La erección de esta estatua constituye la primera etapa de la construcción del templo, que fue edificado en torno a la imagen divina (vs. 248-249). La danza en círculo, en tanto, equivale a la danza de las ninfas en torno a la diosa misma (vs. 170-182), llevada a cabo en sitios bien conocidos por sus santuarios de Ártemis (Delos, Pítane, Limnas, Alas Arafénides, Táuride), que se convierte así en modelo mítico para la danza cultual de las Amazonas, y para el Artemision (cuyos cimientos se echaron en torno a la $\beta \rho \varepsilon ́ \tau \alpha \varsigma)$. Así como Helios contempla el coro de Ninfas (vs. 181-182), Eos no contemplará nunca un templo más divino y

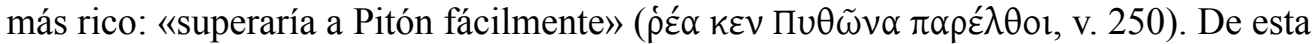
forma, la perspectiva temporal une pasado, presente y porvenir, ya que desde el pasado de su fundación, se augura al santuario un destino tan glorioso como el del templo en Delfos (vs. 249-250). A través de esta anticipación, se evidencia el gran alcance del gesto fundador de las Amazonas, extensible al interés colectivo de la comunidad: Ártemis no será simplemente una diosa venerada por el círculo restringido de las mujeres guerreras, sino una figura popular y honrada por un gran público de fieles.

A través de un catálogo de gestos de veneración llevados a cabo en honor de Ártemis, el Himno ofrece una apertura panorámica extremadamente matizada de su práctica sobre el suelo griego:

Grâce aux hommes et à leur dévotion, Artémis devint una déese reconnue à une très large échelle. Maîtresse de tout espace comme le précise l'Hymne dans ses premiers vers (vs. 33-39), elle se voit atribuer des dons et des offrandes dans plusiers cités de la Grèce. ${ }^{17}$

Por otro lado, se ofrece también un ejemplo de cómo vela Ártemis por su ciudad, defendiéndola de la invasión cimeria con su arco: «para defender Éfeso tienes

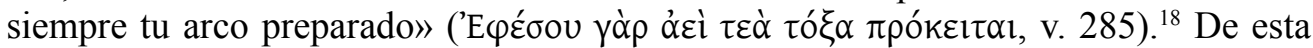
manera, la diosa usa su arco para intervenir en los asuntos humanos, ya sea para castigar a la ciudad de los injustos, o para proteger a quienes gozan de su benevolencia. Nuevamente se puede apreciar en el elemento emblemático del arco, que reúne sus dos aspectos: diosa cazadora, y diosa de la ciudad, y da cuenta de la ambivalencia de Ártemis. Estos aspectos no se contradicen, sino que se complementan. Como «Señora de los animales» (Пótvi $\theta \eta \rho \tilde{\omega} v)$, el epíteto con que es más conocida en la literatura, es también una diosa de iniciación, que supervisa la transición de las niñas a la edad

\footnotetext{
${ }^{17}$ VAMvoury Ruffy (2004: 265).

${ }^{18}$ Este episodio evoca la invasión gálica de Delfos y la defensa por Apolo de su santuario, aludida en Calímaco, Himno a Delos, vv. 171-187.
} 
adulta, e incluso la de los muchachos, en algunas ciudades ${ }^{19}$. Su papel fundamental en la iniciación de los jóvenes, que aparece reflejado significativamente en el mito de las Prétides, relatado por la Oda 11 de Baquílides e insinuado en los vs. 233-236 del Himno, estaría directamente aludido en su epíteto de «Soteira» («Salvadora»), ya que su rol iniciador «salvaba» a la comunidad de la extinción a través del acceso de nuevos miembros ${ }^{20}$.

Al incluir en la última parte del Himno los distintos lugares de culto de Ártemis,

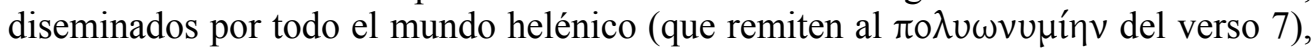
Calímaco incorpora a la imagen literaria de la diosa su dimensión cultual y religiosa en el siglo III a.C., y adapta la Ârtemis de la literatura a la Ártemis del culto contemporáneo. No se trata de un juego literario con el mito, sin interés alguno en las tendencias religiosas de su época, ni de una invención excéntrica y juguetona, como ha asegurado repetidas veces la crítica tradicional, sino de la comprensión profunda de la realidad de su tiempo, con la que puede plasmar la importancia de Ártemis como diosa protectora y principal en numerosas ciudades griegas, desde el Oeste a Asia Menor. La representación literaria de la diosa necesitaba ser renovada para incluir su importantísimo papel de «señora de las ciudades». Para lograrlo, Calímaco escribe un nuevo Himno Homérico. Es sabido que la caracterización de los dioses en los himnos es muy importante e influyente para su retrato en la literatura griega. «Along with the epics, the Homeric Hymns literally created the Panhellenic personalities of divinities $»^{21}$. En el Himno a Ártemis, el poeta recrea el carácter canónico de la diosa para adecuarlo a la realidad cultual, y reelabora los textos de sus predecesores. «He is writing himself in the Homeric tradition and is bestowing on Artemis a portrayal worthy of her status and significance $\rangle^{22}$.

Al no enfocarse solamente en un mito o culto de la diosa, e incluir gran cantidad de leyendas y lugares de culto, Calímaco intenta trazar un cuadro completamente abarcador de Ártemis, adoptando una perspectiva marcadamente panhelénica (otra vez, a semejanza de los Himnos Homéricos ${ }^{23}$ ).

Al definir los elementos de su relato a partir de una perspectiva contemporánea, el hablante inscribe este relato en un campo histórico. El procedimiento del poeta de enumerar los honores rendidos a la diosa en lugares tan distantes, vinculados todos por el mito (y el rito) en un continuum temporal pasado/presente/futuro, se relacionaría con la política cultural de los Ptolomeos:

La mention systématique des actes de dévotion des mortels peut être mise en parallèle avec le projet politique des Ptolémée de maintenir en Égipte, et à Alexandrie en particulier, l'heritage culturel de la Grèce metropolitaine. La démarche de Callimaque ne relève pas uniquement d'une nostalgie du passé culturel et religieux grecs, mais

${ }^{19}$ Con respecto a la relación entre lo salvaje y los ritos de iniciación, cf. BuRKERT (1985: pág. 151) y BREMER (1994: pág. 17).

${ }^{20}$ BREMER (1994: pág. 17).

${ }^{21}$ Petrovic (2010: pág. 222 y n. 52). Sobre la importancia de los textos poéticos en la caracterización de los dioses griegos, véase BURKERT (1985: págs. 119-125).

${ }^{22}$ Petrovic (2010: pág. 226).

${ }^{23}$ Sobre el panhelenismo de los Himnos Homéricos, véase Strauss-Clay (1997: págs. 499-500). 
d'une attitude typiquement coloniale, symptomatique de ceux que s'enracinent dans une nouveau territoire ${ }^{24}$.

La abundancia de cultos y de ofrendas enumeradas en el Himno da una idea de la autoridad extendida del dios en un nivel panhelénico. De esta forma se sitúa al receptor del poema (habitante de Alejandría) en la sucesión de un linaje del cual en adelante él formará parte, y se produce una relación implícita entre él y el mundo griego representado. Ese procedimiento puede ser puesto en paralelo con la política cultural y religiosa de los Ptolomeos que aspira a favorecer la implantación de las prácticas rituales griegas en Egipto, a mantener las relaciones con la cultura griega clásica y a recuperar una parte de su auge cultural. Así, el emigrante griego podía encontrar en Egipto los referentes políticos, culturales y religiosos necesarios para el mantenimiento de su identidad helénica ${ }^{25}$. Asimismo, la presentación de Ártemis en forma panhelénica, con sus santuarios diseminados en todo el mundo conocido, contribuye a mostrarla en forma cosmopolita, un rasgo que desde siempre se ha atribuido a Alejandría. Y Alejandría es, según antes dijimos, la ciudad sobre la que Ártemis ha extendido sus bendiciones, pues en ella mora el poeta que canta su Himno.

\section{BIBLIOGRAFÍA}

Bing, Peter \& Uhrmeister, Volster (1994), «The Unity of Callimachus' Hymn to Artemis», JHS, 114, 19-34.

BREMER, Jan N. (1994), Greek Religion, Oxford.

Burkert, Walter (1985), Greek Religion, Cambridge.

Petrovic, Ivana (2010) «Transforming Artemis: from the Goddess of the Outdoors to City Goddess») en: Bremer, Jan N. \& Erskine, Andrew (eds.), The Gods of ancient Greece. Identities and transformations, Edinburg.

Stephens, Susan (2003) Intercultural Poetics in Ptolemaic Alexandria, California.

Strauss-Clay, Jenny (1997) «The Homeric Hymns», en: Morris, Ian \& Powell, Barry (eds.), A new companion to Homer, Leiden.

Vamvoury Ruffy, Maria (2004) Le fabrique du divin. Les Hymnes de Callimaque à la lumière des Hymnes homèriques et des Hymnes épigraphiques, Liège: Kernos, Suppl. 14.

${ }^{24}$ VAMVOURY RuFFy (2004: pág. 260).

${ }^{25}$ VAmVoury Ruffy (2004: págs. 260, 281 y 290). Sin embargo, debe recordarse que la política lágida no implicaba una política de discriminación hacia los indígenas VAMVOURY RufFy (2004: pág. 282 y n. 237). Sobre el «bilingüismo» de la cultura alejandrina, véase StePHENS (2003). 